\title{
Valorization of Agricultural Residues by Fractionation of their Components
}

\author{
Luis Jiménez* and Alejandro Rodríguez
}

Departamento de Ingeniería Química, Universidad de Córdoba, Spain

\begin{abstract}
The combined production of the most abundant agricultural residues in Spain (viz. cereal straw, sunflower stalks, vine shoots, cotton stalks, olive, orange and peach tree prunings, and horticultural and related residues) amounts to over 50 million tons per year, more than $20 \%$ of which is generated by Andalusia alone.

Agricultural residues must be disposed of for various reasons including the facts that they promote contamination and pest growth, occupy large expanses of land and hinder agricultural work. Ideally, the disposal method used should allow their major components (cellulose, hemicellulose and lignin) or their chemical potential energy to be exploited.

Agricultural residues can be valorized by converting their components jointly (combustion, pyrolysis, gasification, liquefaction) or separately (fractionation).

The most useful method for exploiting such components separately involves isolating cellulose fibres for papermaking purposes. In recent times, this valorization method has led to the development of the biorefining concept. Biorefining involves the fractionation or separation of the different lignocellulosic components of agricultural residues with a view to their integral exploitation rather than the mere use of cellulose fibre to obtain paper products.

Biorefining replaces the classical pulping methods based on Kraft, sulphite and soda reagents with a hydrothermal treatment followed by organosolv pulping. The hydrothermal treatment provides a liquid phase containing hemicellulose decomposition products [both oligomers and monomers (glucose, xylose, arabinose)] and a solid phase rich in cellulose and lignin. By contrast, the organosolv process gives a solid fraction (pulp) and a residual liquid fraction containing lignin and other useful substances for various purposes.
\end{abstract}

Keywords: Agricultural residues, biorefinery, fractionation, pulping, hydrothermal treatment.

\section{INTRODUCTION}

Agricultural residues are highly abundant in Spain (particularly in the Andalusian region). The annual production of the major residues in the country (viz. cereal straw, sunflower stalks, vine shoots, cotton stalks, olive, orange and peach tree prunings, and horticultural and related residues) is estimated to exceed 50 million tons of which more than $20 \%$ is generated in Andalusia [1].

Agricultural residues consist mainly of cellulose and lignin, which jointly account for $85-90 \%$ of their dry matter content; the remaining 15-10\% includes fat, wax, ash, simple sugars, starch, essential oils, pectins, gums and tannins, among other substances [2]. The body of cellulose materials present in these residues is known as "holocellulose" and includes three fractions ( $\alpha$-cellulose, $\beta$-cellulose and $\gamma$ cellulose, the combination of the latter two being referred to as "hemicellulose").

Table 1 shows the production of various agricultural products in Spain and Andalusia over the period 2005-2007

*Address correspondence to this autor at the Departamento de Ingeniería Química, Universidad de Córdoba, Spain; Tel: +34 9572186 25;

Fax: +34 9572186 58; E-mail: iq1jiall@uco.es
[1]. If the production figure for each product is assumed to be similar to the amount of residues it generates, then the combined production of residues of the major crops in Spain can be estimated to be in the region of 50 million ton each year and that in the Andalusian region alone about 10 million.

\section{VALORIZATION OF AGRICULTURAL RESIDUES}

Agricultural residues must inevitably be disposed of in order to avoid contamination, pest growth, occupying large expanses of land and hindering agricultural work. Residues can simply be eliminated to avoid these problems or exploited for specific components or their chemical potential energy. Obviously, the latter choice is to be preferred since, at the very least, it can reduce disposal costs or even yield some profit.

Agricultural residues can be exploited by separating their components in order to obtain cellulose fibre for making pulp and paper. Also, they can be used to extract other components such as sugars or starch, which have a much lesser economic significance. Recently, however, a new trend to the integral exploitation of lignocellulosic materials (agricultural residues included) has developed and led to their "biorefining", which involves the fractionation or separation 
Table 1. Annual Production of Various Agricultural Products in Spain and Andalusia (in Thousands of Tons/Year)

\begin{tabular}{|c|c|c|c|c|}
\hline Agricultural product & Area & Year 2005 & Year 2006 & Year 2007 \\
\hline \multirow[t]{2}{*}{ Wheat } & Andalusia & 708.1 & 1732.5 & 1530.1 \\
\hline & Spain & 4026.7 & 5575.8 & 6376.9 \\
\hline \multirow[t]{2}{*}{ Barley } & Andalusia & 50.2 & 265.0 & 323.6 \\
\hline & Spain & 4626.0 & 8318.4 & 11684.0 \\
\hline \multirow[t]{2}{*}{ Oats } & Andalusia & 36.8 & 146.2 & 175.2 \\
\hline & Spain & 542.1 & 922.6 & 1274.2 \\
\hline \multirow[t]{2}{*}{ Maize } & Andalusia & 582.6 & 330.9 & 262.8 \\
\hline & Spain & 8025.3 & 7501.0 & 3647.9 \\
\hline \multirow[t]{2}{*}{ Rice } & Andalusia & 326.8 & 210.1 & 172.4 \\
\hline & Spain & 824.1 & 746.1 & 701.3 \\
\hline \multirow[t]{2}{*}{ Potato } & Andalusia & 249.2 & 175.0 & 172.2 \\
\hline & Spain & 2100.1 & 2054.6 & 2049.4 \\
\hline \multirow[t]{2}{*}{ Cotton } & Andalusia & 338.0 & 139.7 & 123.7 \\
\hline & Spain & 343.8 & 141.2 & 125.2 \\
\hline \multirow[t]{2}{*}{ Sunflower } & Andalusia & 155.0 & 248.7 & 367.3 \\
\hline & Spain & 381.3 & 606.8 & 743.4 \\
\hline \multirow[t]{2}{*}{ Tomato } & Andalusia & 1439.5 & 749.2 & 618.5 \\
\hline & Spain & 6524.8 & 4389.3 & 3696.0 \\
\hline \multirow[t]{2}{*}{ Strawberry } & Andalusia & 307.0 & 321.3 & 253.0 \\
\hline & Spain & 320.8 & 333.5 & 263.9 \\
\hline \multirow[t]{2}{*}{ Onion } & Andalusia & 121.1 & 148.2 & 169.4 \\
\hline & Spain & 1006.0 & 1115.2 & 1176.5 \\
\hline \multirow[t]{2}{*}{ Orange } & Andalusia & 1180.3 & 1432.4 & 1282.3 \\
\hline & Spain & 5107.3 & 6554.2 & 5444.5 \\
\hline \multirow[t]{2}{*}{ Peach } & Andalusia & 133.3 & 173.2 & 150.0 \\
\hline & Spain & 1260.9 & 1255.6 & 1149.7 \\
\hline \multirow[t]{2}{*}{ Grape } & Andalusia & 235.6 & 244.5 & 258.5 \\
\hline & Spain & 6053.0 & 6401.5 & 6013.0 \\
\hline \multirow[t]{2}{*}{ Olives } & Andalusia & 3116.2 & 4544.6 & 4790.7 \\
\hline & Spain & 4021.7 & 5472.5 & 5787.6 \\
\hline
\end{tabular}

into their components with a view to their individual exploitation rather than the mere use of part of their cellulose to obtain paper with a classical (Kraft, sulphite, soda) pulping method. The fractionation of lignocellulosic materials by thermal treatment in an aqueous medium (a hydrothermal treatment) and their processing in an organic solvent (an organosolv process) have been the subject of some study [3].

Fig. (1) depicts various procedures for valorizing agricultural residues by transforming their components without a prior separation [4]. This requires subjecting the residues to a series of physical operations (downsizing, classification, drying, agglomeration) intended to facilitate subsequent processing. Once conditioned, the lignocellulosic materials in agricultural residues can in fact be efficiently subjected to physico-chemical and biochemical valorization treatments. The former, also known as "thermal" or "dry" treatments, involve high temperatures and require the use of sophisticated equipment operating during short processing times. On the other hand, biochemical (wet) processes use low temperatures, simple equipment and long processing times. The physico-chemical processes used in this context include combustion to generate heat; gasification to obtain synthetic or combustion gases; pyrolysis to obtain gases, liquids, solids and various chemicals; and liquefaction to produce liquid fuels. The biochemical processes give bioalcohol (as fuel), biogas (burning gas) and single-cell protein (animal feedstuff). 


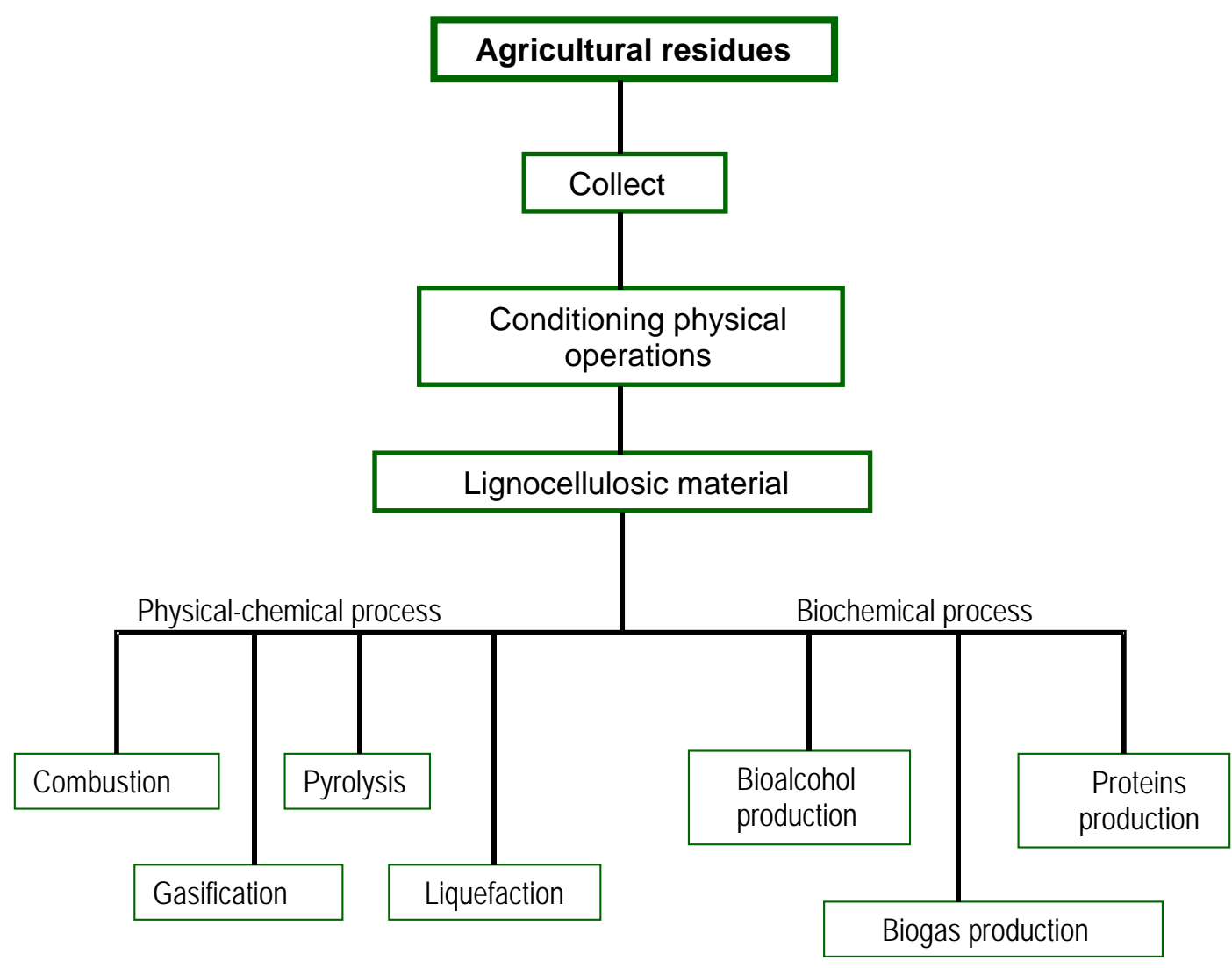

Fig. (1). Valorization of agricultural residues without separation of their components.

\section{FRACTIONATION OF AGRICULTURAL RESIDUES}

The processes currently used to valorize agricultural residues fractionate their individual components in order to recover those with the highest interest. This is made difficult by the inability to efficiently isolate cellulose, hemicellulose and lignin without degrading their chemical structure. The most widely used fractionation methods are based on the following principles:

(a) Conventional pulping, which isolates the cellulose fraction to obtain pulp for papermaking purposes or as the source of various chemicals.

(b) Dissolution of lignin in an organic solvent (an organosolv process) in order to obtain a lignin-rich liquid fraction and a cellulose-rich solid fraction that are used to produce lignin and cellulose pulp, respectively.

(c) Hydrothermal treatment, which provides a liquid fraction rich in hemicellulose degradation products mainly and a solid fraction essentially consisting of $\alpha$-cellulose and lignin.

\section{Conventional Pulping}

Fig. (2) shows a simple, general flow chart for the pulping process $[3,5]$. The chart includes some operations that are not always needed (debarking and/or demarrowing of the raw material) or used (purifying, cleaning and/or bleaching of the pulp). Also, cooking, disintegration and washing can usually be done with the same equipment as impregnation of the raw material and drainage of spent or residual cooking liquor.
By contrast, storage of the raw material is unavoidable since residues are usually collected over short periods (particularly in the case of agricultural residues) and processed over much longer ones in order to exploit the processing facilities throughout the year. Residual moisture is the most influential among storage-related variables and should in theory be as low as possible in order to facilitate conservation of the raw material; however, this requires a substantial energy investment, so an acceptable compromise between storage at a low and a high moisture level must usually be made. Deterioration of agricultural residues by effect of moisture usually takes the form of fungal, bacterial and yeast growth above some moisture levels and leads to the formation of acid enzymes capable of attacking lignocellulosic materials and causing hydrolysis of their carbohydrates and, to a lesser extent, oxidation of lignin [2]. This entails keeping the moisture content of stored agricultural residues below specific levels in order to minimize development of microbes. There is practical evidence that agricultural residues should be stored at a relative humidity not exceeding 45 $55 \%$ [6]; however, wetting the raw material has proved efficient in blocking access to active sites available for oxygen to interact with microbes, which occurs at temperatures from 20 to $40{ }^{\circ} \mathrm{C}$ [2]. The raw material can be stored in various formats including long and short wood pieces, chips or even sawdust. Storing large amounts of raw material can require substantial investments in circulating capital; also, the need to maintain the storage facilities can raise labour costs and both factors in combination can detract from profitability.

The cutting operation is required when the raw material reaches the factory as logs. Debarking is needed for ligneous 


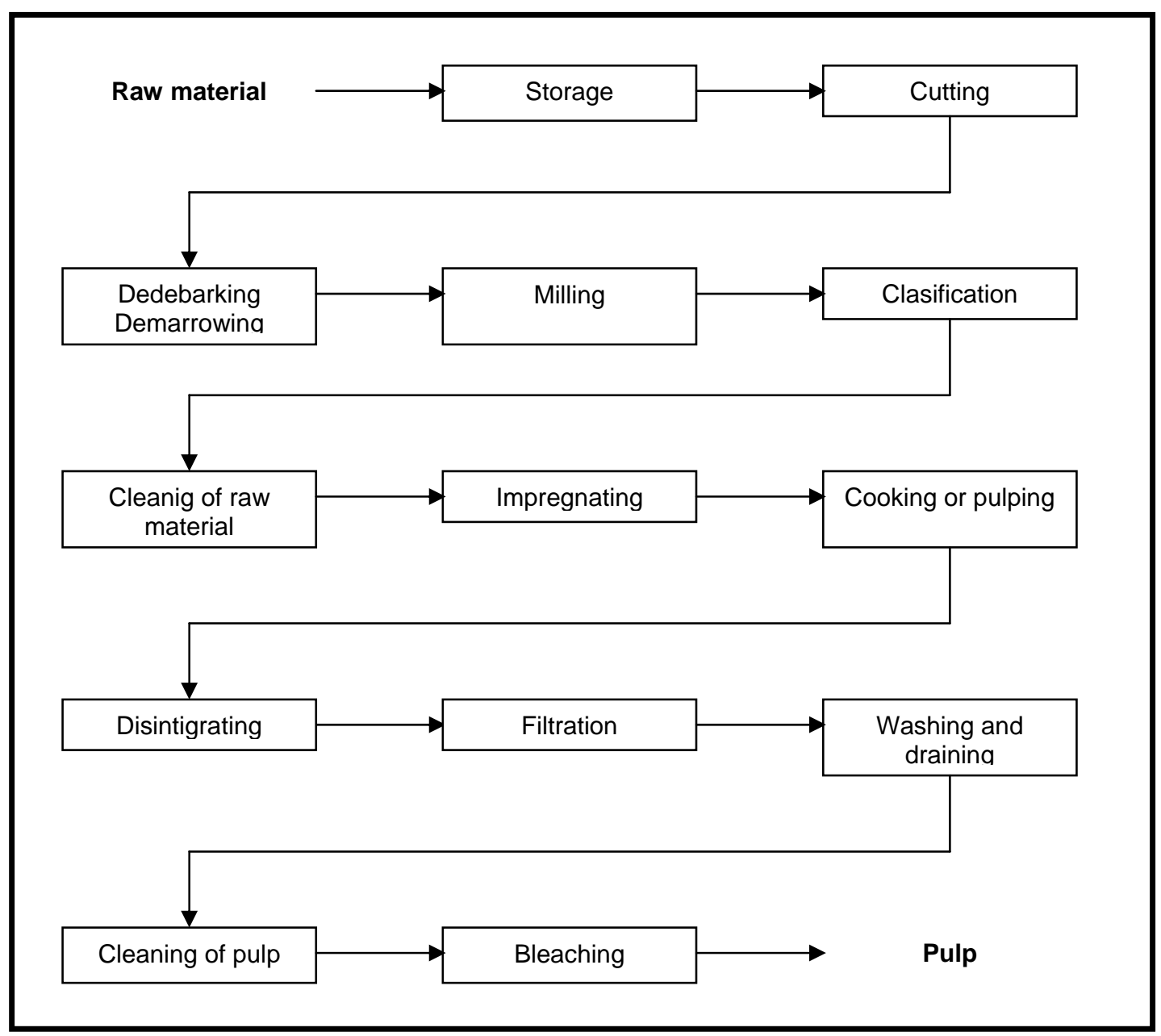

Fig. (2). Pulping of lignocellulosic materials.

plants since bark consumes large amounts of cooking reagents and contains impurities that can pass into pulp and hinder efficient purification, ultimately leading to paper of poor quality. Many agricultural residues come from marrow plants and require demarrowing for the same reason as others require debarking. Both operations are usually cumbersome and expensive as they use friction machines and hydraulic treatments based on cutting blades and chemicals [2].

The milling or chipping, classification or sieving and cleaning or purifying operations give chips of appropriate size and containing none of the extraneous substances frequently accompanying the raw material (e.g. wires, strings, plastic, grains, sand, dust) [5,7].

Impregnation of the raw material involves soaking it in the pulping reagents in order to facilitate access to chip surfaces. The need for impregnation increases with increasing chip size and compaction of the raw material. The operation is completely unnecessary for properly chipped materials and some agricultural residues [5]. When needed, it is performed in appropriate vessels occasionally, in the cooking reactor itself.

Cooking the raw material involves isolating cellulose fibres from the lignin fibres to which they are bound by using a mechanical or chemical procedure, or a combination thereof. This produces mechanical, chemical and semichemical pulp, respectively. Mechanical procedures use the mechanical energy of a mill or refiner to release cellulose fibres without the need for any chemicals; although the pulp is typically obtained in a high yield, it contains some lignin by effect of fibre release being incomplete. In some cases, the use of steam or a highly diluted reagent facilitates softening of the lignin, but never its complete removal. The resulting pulp is termed stone-mill, refiner, thermomechanical, chemomechanical or chemothermomechanical pulp [3]. Chemical cooking procedures use chemicals to dissolve or degrade lignin to an extent allowing the release of cellulose fibres by using very little mechanical energy. Pulp yield is low and the raw material inefficiently exploited as a result. In fact, after the chemical action of the reagent is exhausted, the material chips may require disintegration in a mill or refiner in order to release individual cellulose fibres in some cases, however, simply lowering the pressure to atmospheric level can suffice for this purpose. Specially prominent among chemical cooking processes are those based on sulphate (Kraft), sulphite and soda reagents, and those using an organic solvent $[8,9]$.

A pulp yield in between those of mechanical and chemical pulp can be achieved by using milder conditions than in chemical pulping processes in order to lessen lignin degrada- 
tion; an additional, mechanical treatment is usually needed to obtain semi-chemical pulp. The chemical treatment used in semi-chemical pulping processes differs from the chemical pretreatment employed in mechanical processes; thus, the latter is intended simply to soften the lignin, whereas the former is additionally intended to remove it in part. A number of semi-chemical pulping processes now exist that use various reagents including sulphate, sulphite and sulphurfree chemicals [2, 7].

Residual cooking liquor is separated by filtration prior to washing of cellulose fibre with water or, occasionally, fresh liquor. Some types of pulp require additional filtration or draining in order to remove as much washing liquid as possible [5].

Pulp purification removes impurities, whether heavier or bulkier than the fibres, by using a cyclone, centrifuge, sieve or screen [2].

Finally, bleaching the pulp removes some of its components and/or alters others by using one or more chemical reagents in one or several steps. High-yield pulp (mechanical and semi-chemical pulp, mainly) should only be altered as regards chromophoric groups in lignin in order to avoid yield losses. The use of peroxides, hydrosulphites or ozone in a single step results in fairly low pulp brightness. All types of chemical pulp, and some of semi-chemical pulp, require higher brightness that can only be achieved by using multistep bleaching sequences. The increasing pressure to reduce pollution that has developed over the last few decades has fostered the development of new, totally chlorine-free (TCF) bleaching sequences using oxygen, ozone or hydrogen peroxide for this purpose $[2,3]$.

\section{Organosolv Pulping}

The steady growth of environmental concern in developed countries must be reconciled with their increasing demand for pulp. This need has led researchers to find alternative raw materials such as agricultural residues and also to develop new, organosolv pulping processes. Organosolv processes use sulphur-free reagents and low-output facilities to obtain high-quality pulp and paper products in high yields at a low cost. In addition, they are highly efficient in using raw materials and afford the obtainment of a number of byproducts as a result [8-12].

Organosolv processes only started to challenge the supremacy of traditional chemical pulping processes after the 1970 s, when they emerged as effective choices for overcoming some of their traditional problems (e.g. off odours, low yields, high pollution, large investments, and high water, energy, raw material and reagent consumption). The earliest organosolv processes were simply modified versions of previous classical processes but soon gave way to new, sulphurfree treatments. These processes posed new problems such as the difficulty of recovering the reagents and the polluting nature of the effluents. The actual usefulness of organosolv processes as alternatives to the classical processes was assessed and the former found to ensure integral exploitation of the raw material, so much so that they were regarded as the means to obtain hydrolysable cellulose, lignin phenol polymers and sugars rather than as pulping processes proper. In the 1990s, the Kraft process still defied competition from all others; however, its environmental unfriendliness, high investment costs and low profitability on the small and medium scales fostered a search for new pulping processes not only avoiding their problems but also allowing integral use of the raw materials in order to obtain various substances of interest in addition to cellulose pulp. This is how so-called biorefining of lignocellulosic materials was born. Finally, a new line of research was started in the mid-1990s towards the efficient delignification of alternative raw materials such as agricultural residues by organosolv pulping [8,9].

Fig. (3) depicts a typical organosolv process. As can be seen, the raw material is added jointly with recycled organic solvent and the fresh solvent which is intended to replenish any solvent lost during the recovery operation and additives to the cooking reactor. After a preset processing time, the reactor contents are unloaded into a washer in order to separate a solid fraction (the pulp) and a liquid fraction containing the black liquor [viz. solvent plus dissolved products (lignin, mainly)] and the washing agent. Then, the liquid fraction is used to isolate lignin, sugars and the solvent, the last being recycled to the cooking reactor.

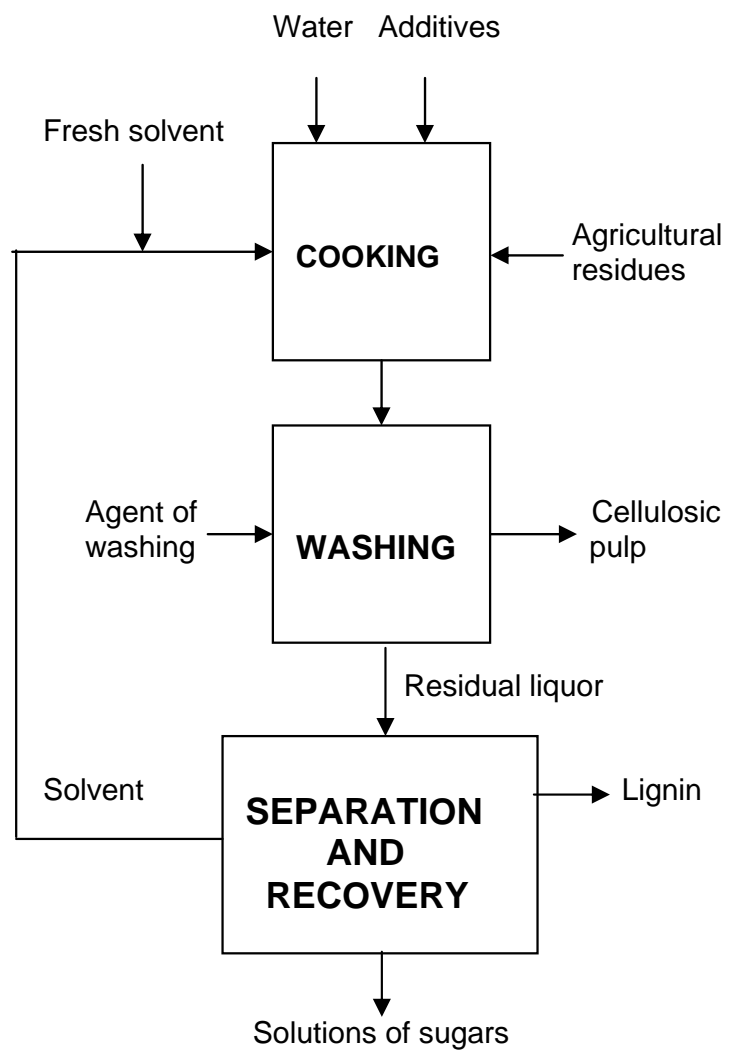

Fig. (3). Fractionation of lignocellulosic materials with organic solvents.

The high cost of organic solvents, their difficult recover and very often high toxicity have fostered the use of lowmolecular weight aliphatic alcohols (ethanol and methanol, mainly). These two alcohols are the oldest delignifiers; in fact, Kleinert used them separately in a $50 \%$ proportion at $195{ }^{\circ} \mathrm{C}$ in the absence of catalyst on steamed chips as early as 1974. This treatment is similar to that of the Alcell process (with ethanol), which has gained widespread acceptance. The increased use of alcohols is reflected in their being the 
sole organosolv reagents employed on the pilot plant and industrial scales. Also in wide use at present are the ASAE, Organocell, ASAM, ASAE, NAEM and IDE processes [8].

The greatest shortcoming of organosolv processes are their poor performance in the production of quality paper from softwood materials in fact, they can only compete with the Kraft process in this respect for the production of lowgrade paper and board and the potential problems encountered in pulping hardwood, according to the considered species some plant species can result in a high reject rate and poor yield, and require a large amount of refining energy or drastic bleaching.

The Alcell process, which uses ethanol in a 50 vol\% proportion, is one of the best known among those using an alcohol and no catalyst [8, 13]. Its operating conditions are a temperature in the region of $195{ }^{\circ} \mathrm{C}$, a processing time of 60 min and a liquid/solid ratio of $6: 1$ to $7: 1$. The process is especially suitable for hardwood but has provided also good results with alternative raw materials such as bagasse and cereal straw albeit with some problems arising from the presence of large amounts of silica in both. Alcell pulp contains more $\alpha$-cellulose and less hemicellulose than does Kraft pulp; by contrast, it is obtained in higher yields and loses less hemicellulose during refining. In addition, it has a lower reject rate as the likely result of the low viscosity of the mixed ethanol-water solvent facilitating access to chip fibres. The Alcell process is more economical than the Kraft process. Also, Alcell pulp is easily delignified with oxygen (the Kappa number is reduced by up to $70 \%$ ) with little loss of viscosity Kraft pulp can lose up to $50 \%$ under identical conditions. The brightness of Alcell pulp is competitive with that of conventional pulp. Also, the Alcell process gives no off-odours; produces reduced amounts of effluents and pollutants; yields byproducts of a higher quality and in greater amounts; is more efficient in using raw materials; can be more readily applied to smaller amounts of raw material and implemented on a smaller scale than the Kraft process; and uses less energy than the classical process. However, it has some disadvantages. Thus, it is inapplicable to softwood, subject to increased production costs by effect of the high price of ethanol and the reagents needed to recover the target byproducts, and uses more energy than the Kraft process. Some of these disadvantages, however, are offset by the additional profit resulting from byproduct sales.

Hardwood can be pulped without a catalyst. Some plant species, however, require a physico-chemical pretreatment and several cooking steps in order to ensure efficient delignification and a high yield. On the other hand, pulping softwood invariably requires using a catalyst. Thus, the patented process of Paszner and Cho uses a magnesium salt in addition to the alcohol [14]. One other pulping process involving a catalyst is that based on the sodium-bicarbonate-water system and methylanthraquinone as catalyst, which have been applied to some poplar varieties. With softwood, the yield and lignin content of the pulp can be increased relative to leafy wood by replacing the bicarbonate with oxalic acid; however, using propanol instead of ethanol leads to poorer results [8].

The MD Organocell process, which uses ethanol and soda, is a complement, but not a competitor, for the Kraft process, which it can replace in countries having no Kraft pulping facilities [15]. Unlike the Alcell process, the MD Organocell process is applicable to softwood, the resulting pulp having better strength-related properties than Kraft pulp. Also, it can be applied to mixtures of softwood and hardwood, but this requires recovering the soda in addition to the alcohol.

The Organocell process involves a second step with anthraquinone in addition to the first (methanol and soda). Typically, the operation conditions are $17-20 \%$ sodium hydroxide, $0.1 \%$ anthraquinone, 5-30 vol\% methanol, a liq$\mathrm{uid} /$ solid ratio of about $4: 1$, a temperature of $155-170{ }^{\circ} \mathrm{C}$ and a processing time of $60-120 \mathrm{~min}$ [13]. This process has also been applied to alternative raw materials including wheat straw and amaranth [16].

One other widely used organosolv process is ASAM (alkaline sulphite-anthraquinone-methanol), which combines the action of soda, sulphite, anthraquinone and an alcohol. The process uses a chemical load of 15-25\% sodium hydroxide, an alkali $\left(\mathrm{Na}_{2} \mathrm{SO}_{3} / \mathrm{NaOH} / \mathrm{Na}_{2} \mathrm{CO}_{3}\right)$ proportion of 85:15-70:30, 0.05-0.1\% anthraquinone, 15-30 vol\% methanol, a liquid/solid ratio of $3: 1$ to $5: 1$, temperatures of $170-180^{\circ} \mathrm{C}$ and processing times of $60-150$ $\min$ [13]. The results are similar to those of the Kraft process in terms of paper strength and to those of the sulphite process as regards brightness. The ASAM process has some advantages over the Alcell and Organocell processes (e.g. Alcell paper has better breaking length, however). Also, Alcell pulp is comparable to Kraft pulp in many respects, uses the same types of facilities and reagents as the sulphite process in addition to dedicated equipment to recover methanol, and provides cleaner, brighter raw pulp [17]. However, it has some disadvantages such as the need for high pressures and temperatures, larger capital investments and greater amounts of sodium sulphite; and more complicated reagent recovery, which requires a methanol recovery system and an appropriate unit to convert sulphides into sulphites [8]

The ASAE process is a variant of the ASAM process which replaces methanol with ethanol. Its optimum operating conditions for pulping pine wood, for example, are $20 \%$ sulphite, $50 \%$ ethanol and a processing time of $150 \mathrm{~min}$ at a high temperature. The resulting yield, viscosity, brightness and mechanical properties are all better breaking length excepted than those of Kraft pulp [18]. This process has been applied to cotton stalks [19].

Although the ASAM, ASAE and Organocell processes are efficient in delignifying both hardwood and softwood, they are confronted with the difficulty of recovering the reagents, which is as complex as in the Kraft process and even more so than in the Alcell process. On the other hand, these processes release no sulphur compounds and are thus more environmentally benign than the Kraft process. Finally, the resulting pulp is brighter and amenable to bleaching with a totally chlorine-free (TCF) sequence.

The NAEM process is suitable for both softwood and hardwood, as well as for sugarcane bagasse. It uses methanol as solvent and an alkaline-earth salt as catalyst, and produces pulp with a small Kappa number and moderate viscosity. An appropriate post-cooking treatment, however, allows yield, viscosity and various other properties to be improved in relation to Kraft pulp. In fact, the outcome of the NAEM process 
clearly surpasses those of various others (ethanol, sodaethanol, phenol-hydrochloric acid, cresol, ester, ASAM) [8]. There have been some NAEM trials at high pressures [20].

The IDE process involves three consecutive steps (impregnation with concentrated sodium carbonate, cooking with ethanol and extraction with an ethanol-water mixture) and has so far been applied to both hardwood and softwood, as well as to cereal straw and other alternative raw materials $[8,21,22]$.

Other organic solvents widely used for cooking purposes include low-molecular weight organic acids, which are the basis for the Acetocell, Milox and Formacell processes.

The Acetocell process uses acetic acid in combination with hydrochloric or sulphuric acid as catalyst [23]. It is suitable for both hardwood and softwood, and also for bagasse and annual plants. Some variants use acetic acidwater, acetic acid-carbon dioxide or acetic acid-watercarbon dioxide mixtures under supercritical conditions [24]. The process has also been applied to alternative raw material such as rice straw at atmospheric pressure [25].

Pulping hardwood with formic acid has the advantage of a low solvent cost and the ability to use of low pressures and temperatures [26]. The acid has been used to cook various alternative raw materials [27, 28]. The Milox process uses peroxyformic acid, which forms spontaneously upon mixing formic acid in a $80 \%$ proportion with hydrogen peroxide [28]. This process is especially effective for delignifying birch wood in three steps: treatment with peroxyformic acid at $80{ }^{\circ} \mathrm{C}$, treatment with formic acid at $100{ }^{\circ} \mathrm{C}$ and bleaching with hydrogen peroxide to achieve $90 \%$ ISO brightness [29]. The mechanical properties of the resulting pulp are essentially identical with those of Kraft pulp; softwood, however, provides poorer results with the Milox process. The greatest shortcoming of this process is that distilling the reaction mixture to recover the solvent provides an azeotrope containing a $78 \%$ concentration of formic acid, which is inadequate for recycling. The Milox process has been applied to bagasse, rice straw and other alternative plants [30-33] in addition to wood raw materials.

The Formacell process uses a mixture of acetic acid, water and formic acid [34]. Its application to beech, pine and poplar wood provides pulp with a small Kappa number. The process has been used with alternative raw materials [32, 33]. Acetic acid containing sulphuric acid and a phenol has provided good results with birch wood [35]. Finally, the Formacell process has also been implemented with supercritical mixtures of acetic acid, carbon dioxide and water [24].

Dimethylformamide has been increasingly used since recently in the pulping of alternative raw materials [36-38].

Some high-boiling organic solvents such as ethanolamines and ethyleneglycols [9] are especially interesting in this context as they can be used under milder (Kraft-like) conditions than the previous alcohols and organic acids. These cooking solvents have so far been applied to empty fruit bunches (EFB) [39, 40], rice straw [41], olive prunings [42, 43], vine shoots [44-46] and cotton stalks [45].

Other organic solvents including phenols, glycols, esters, acetone, ammonia, amines, formamide, dimethylformamide and dioxane have also been used in organosolv processes. For example, rice straw has been cooked with phenol, acetic acid, formic acid, formaldehyde and acetone [9].

\section{Hydrothermal Treatment}

One of the ways of fractionating lignocellulosic materials is by hydrothermal treatment or autohydrolysis, both of which facilitate depolymerization of hemicellulose (see Fig. 4). These treatments provide an aqueous fraction of hemicellulose containing xylo-oligosaccharides and monosaccharides (xylose, glucose, arabinose) [47-49], and a solid residue consisting largely of cellulose and lignin amenable to pulping. The solid reside can be pulped with a classical or organosolv procedures. The latter have the advantage that they additionally facilitate the isolation of lignin and its use as a source for a wide variety of chemicals, some with a high added value [3, 50-52].

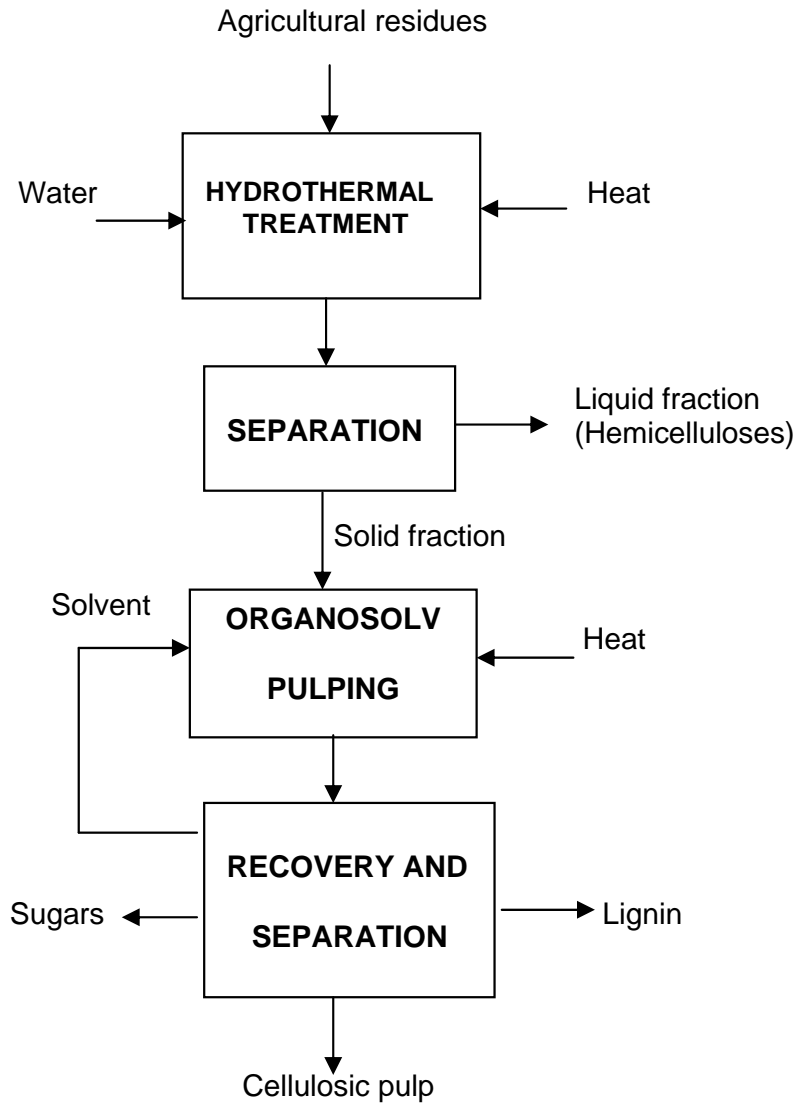

Fig. (4). Fractionation of lignocellulosic materials by hydrothermal treatment.

Hydrothermal treatments can be implemented in various ways. One specially interesting method is steam explosion: following autohydrolysis, the raw material is subject to abrupt depressurization in order to evaporate water contained in its fibres and facilitate disaggregation of the lignocellulose matrix [50]. 
Hemicellulose undergoes autohydrolysis at temperatures above $150-250{ }^{\circ} \mathrm{C}$ in an aqueous medium. Under these conditions, the autoionization of water produces protons that act as catalysts for the autohydrolysis process by attacking acetyl groups present in ester form in hemicellulose heteropolymers and causing the release of acetic acid as a result. The acid provides up to one million times more protons than water; therefore, water protons contribute very little to the hydrothermal treatment once the acid is formed. In addition to completely or partially dissolving hemicellulose, the process causes its efficient transformation into oligosaccharides and monosaccharides with a variety of potential uses.

Other less significant reactions occurring during the treatment include the formation of compounds such as furfural from pentoses and 5-hydroxymethyl-2-furfural (HMF) from hexoses; production of carbon dioxide by decomposition of carboxyl groups in uronic acids; condensation of unstable molecules acting as reaction intermediates; decomposition, under drastic conditions, of acid-sensitive products such as furfural or HMF into formic and levulinic acids; and condensation of various substances with lignin [53-55].

An autohydrolysis treatment has some advantages over acid hydrolysis, namely: greater operational simplicity; a reduced environmental impact as a result of the absence of acid neutralization sludge; and the ability to subject the resulting suspension to abrupt depressurization (steam explosion) in order to disaggregate the lignocellulose matrix and facilitate subsequent processing with a view to the obtainment of cellulose pulp [50].

Hydrothermal treatments can be performed over a wide temperature range. The outcome is influenced by temperature, time, solid concentration and particle size. The temperature is always higher than $100{ }^{\circ} \mathrm{C}$, below which no autohydrolysis occurs. Favouring depolymerization of hemicellulose requires establishing an appropriate upper limit for this variable. Thus, in an weakly acidic medium, ether bonds in lignin start to break at $160-180{ }^{\circ} \mathrm{C}$, whereas $\alpha$-cellulose depolymerization starts above $210{ }^{\circ} \mathrm{C}$. The operating time can range from a few seconds to several hours. When using a relatively high temperature, the heating time (heating ramp) used to reach the target operating temperature can be very important. In some cases, the heating time can be much longer than the operating or reaction time; by contrast, the cooling time is comparatively short (the cooling rate is in the region of $30{ }^{\circ} \mathrm{C} / \mathrm{min}$ ) and has little influence on the results. The solid concentration (or solid-liquid ratio) typically ranges from 2 to $40 \mathrm{~g}$ water/g lignocellulosic material, but is usually set at about $10 \mathrm{~g} / \mathrm{g}$. A high solid-liquid ratio facilitates extraction of hemicellulose but is costly; on the other hand, a low ratio can initially be economical but subsequently result in impaired diffusion and transfer of the reaction products. Also, a small particle size facilitates hydrothermal treatment but requires milling, which raises energy expenses. Typically, laboratory treatments use particles $0.5-$ $1.0 \mathrm{~cm}$ in size, and industrial and pilot-plant treatments chips of several centimetres. The study of the influence of particle size on the process has been considered by some authors [53$55]$.

The use of drastic operating conditions causes lignocellulose to be dissolved to a large extent and hence unwanted products (furfural, HMF) to be produced in high proportions. This requires controlling a number of operating variables in order to maximize the content in hemicelluloses of the liquid fraction with a view to producing monosaccharides (xylose, glucose, arabinose) or oligosaccharides both of which are desirable products while minimizing the formation of degradation products. The use of appropriate conditions allows $60-85 \%$ of the total amount of hemicellulose in the raw material to be recovered as oligosaccharides and monosaccharides. The proportion of oligosaccharides invariably surpasses that of monosaccharides and often accounts for more than one half of the initial hemicellulose content. The inability to quantitatively recover sugar oligomers and monomers in the liquid fraction is a result of the presence of degradation reactions (e.g. the formation of furfural and HMF), which develop to an extent dependent on the particular operating conditions and varying widely for the same raw material [56-58].

The ability of hydrothermal treatments to provide delignifiable solid residues in addition to the liquid fraction affords the additional production of cellulose pulp by integrating the recovery of sugar byproducts with pulping as well as with lignin recovery if an organosolv process is used [5357].

The liquor remaining after the autohydrolysis of lignocellulosic materials consists largely of oligosaccharides and monosaccharides; by appropriate transformation, separation and purification, these sugars can be used in various fields, namely: agriculture (growth boosters and accelerators); animal (pet, fish) feeding; medicine (prevention and treatment of gastrointestinal diseases, and treatment of osteoporosis, otitis and hair and skin problems); human nutrition (reinforced foodstuffs, special food for antiobesity diets, symbiotic foods containing microorganisms in addition to nutritional principles with healthy effects) [50].

Hydrothermal treatments have been applied to various types of agricultural residues including vine shoots [56], sunflower stalks [54], rice straw [59] and legumes [57, 58].

\section{ACKNOWLEDGEMENTS}

The authors are grateful to Ecopapel, S.L. (Écija, Seville, Spain) for their support, and to Spain's DGICyT for funding this research within the framework of Projects PPQ200765074-C02-01 and TRACE2009-0064.

\section{REFERENCES}

[1] Ministerio de Agricultura, Pesca y Alimentación. Madrid.

[2] Colom JF. Introducción a la historia papelera. Iniciación al conocimiento del papel. Servicio de Publicaciones de la ETSII.2005; Terrassa. Barcelona 2007.

[3] Jiménez L, Ed. Pastas celulósicas de materias primas alternativas a las convencionales.. Gráficas Sol; Écija, Spain 2005.

[4] Jiménez L, Mata FJ, Sicilia F, et al. Procesos de conversión de biomasa residual en energía. Energía 1988-89; 11-12, 131-138; 3-4, 99-108; 11-12, 105-109.

[5] Jiménez L, Pérez A. El proceso de fabricación del papel. El Papel 2006; 127(8/9): 58-61.

[6] Jiménez L, Angulo V, Serrano L, Moral A, Rodríguez A. Almacenamiento de materias primas para pastas celulósicas. Ing Quím 2008; 40(4): 154-9.

[7] Gullichsen JT, Pulapuro H. Chemical pulping. Fapet Oy: Finlandia 2000; vol. 6A, 6B. 
[8] López F, Alfaro A, Jiménez L, Rodríguez A. Los alcoholes como disolventes orgánicos para la obtención de pastas celulósicas. Afinidad 2006; 63(523): 174-82.

[9] Rodríguez A, Jiménez L. Pulping with organic solvents other than alcohols. Afinidad 2008; 65(535): 188-96.

[10] Hergert HL. Developments in organosolv pulping. An overview. En: Environmental friendly technologies for the pulp and paper industry. Young RA, Akhtar M. New York: John Wiley and Soong Inc. 1998

[11] Neves FL, Neves JM. Organosolv pulping: a review. Papel 1998; 559(8): 48-52.

[12] Muurinen E. Organosolv pulping. A review and distillation study related to peroxyacid pulping. Thesis Doctoral. Chemical Engineering Process. University of Oulu: Finland 2000.

[13] Stockburger P. An overview of near-commercial and commercial solvent-based pulping processes. Tappi J 1993; 76(6): 71-4

[14] Paszner L, Cho HJ. Organosolv pulping: acid catalysis options and their effect on fiber quality and delignification. Tappi J 1989; 72(2): 135-42.

[15] Dahlmann G, Schroeter MC. The Organocell process pulping with the environment in mind. Tappi J 1990; 73(4): 237-40.

[16] Pekarovicova A, Pecarovic J, Joyce TW. Comparison of amaranthus and wheat straw organocell pulping. Cell Chem Technol 1999; 33(1-2): 125-33

[17] Obracea P, Gavrilescu D, Stancana R. Organosolv pulping of wood alkaline-media. 1. ASAM pulping of beech wood at lowtemperature. Cell Chem Technol 1994; 28: 339-49.

[18] Kirci H, Bostanci S, Yalinkilic MK. A new modified pulping process alternative to sulfate method alkaline-sulfite-anthraquinoneethanol (ASAE). Wood Sci Technol 1994; 28(2): 89-99.

[19] Kirci H, Eroglu H. Alkali sulfite anthraquinone ethanol (ASAE) pulping of cotton stalks (Gossypium hisutum L.). Turk J Agric Forestry 1997; 21(6): 573-7.

[20] Lohrasebi AH, Paszner L. Predictive modelling of high-pressure maem-catalyzed (HP-Alpulp) organosolv pulping of spruce. Tappi J 2001; 84(4): 69-69.

[21] Ciovica S, Lonnberg B, Lonnquist K. Dissolving pulp by the IDE pulping concept. Cell Chem Technol 1998; 32(3/4): 279-90.

[22] Quader MMA, Lonnberg B. Pulp and chemical cellulose obtained with oil palm empty fruti bunches by modified IDE process. JIRCAS Working Report 2005; vol. 39: pp. 47-53.

[23] Neumann N, Balser K. Acetocell. An innovative process for pulping, totally free from sulfur and chlorine. Papier 1993; 47(10): 1623.

[24] Kiran E, Balkan H. High-Pressure extraction and delignification of red spruce with binary and ternary mixtures of acetic-acid, water and supercritical carbon-dioxide. J Supercrit Fluid 1994; 7(2): 7586.

[25] Pan XJ, Sano Y, Ito T. Atmospheric acetic-acid pulping of rice straw. II. Behaviour of ash and silica in rice straw during atmospheric acetic-acid pulping and bleaching. Holzforschung 1999; 53 (1): 49-55

[26] Erismann NM, Freer J, Baeza J, Durán N. Organosolv pulping. VII. Delignification selectivity of formic-acid pulping of Eucalyptus grandis. Biores Technol 1994; 47: 247-56.

[27] Ligero P, Villaverde JJ, Vega A, Bao M. Organosolv delignification of cardoon (Cynara cardunculus) stems with formic acid. Afinidad 2007; 64(527): 48-53

[28] Qiliang T, Shiyu F, Huaiyu Z, Xinsheng C, Lucian L. Kinetic modeling of formica acid pulping of bagasse. J Agric Food Chem 2008; 56(9): 3097-101.

[29] Poppiuslevlin K, Mustonen R, Huovila T, Sundquist J. Milox pulping with acetic-acid peroxyacetic acid. Pap Puu-Pap Tim 1991; 73: 154-8.

[30] Pérez SD, Terrones MGH, Grelier S, et al. Peroxyformic acid pulping of Eucalyptus grandis wood chips and sugar cane bagasse in one stage and characterization of isolated lignins. J Wood Chem Technol 1998; 18(23): 333-65.

[31] Lam HQ, Bigot Y, Delmas M, Avignon G. Formic acid pulping of rice straw. Ind Crops Prod 2001; 14(1): 65-71.

[32] Sarwar, J.M. Formic acid pulping of bagasse. Blangladesh J Sci Ind Res 2006; 3-4: 245-50.

[33] Sarwar JM, Nasama CDA, Khalidul IM. Formic acid/acetic acid pulping of kash (Saccharum spontaneum), jute (Corcorus capsularis) and dhaicha (Sesbania aculeatya). Ippta J 2007; 19(2): 115-8.
[34] Saake B, Lummitsch S, Mormanee R, Lehnen R, Nimz HH. Production of pulps using the Formacell process. Papier 1995; 49(10): V1-V7.

[35] Sano Y, Shimamoto S. Pulping of birch wood at atmosphericpressure with aqueous acetic-acid containing small amounts of sulfuric-acid and phenols. Mokuzai Gakkaishi 1995; 41(11): 1006-11.

[36] Ghozatloo A, Mohammadi-Rovshandeh J, Hashemi SJ. Optimization of pulp properties by dimethyl formamide pulping of rice straw. Cell Chem Technol 2006; 40(8): 659-67.

[37] Rezayati-Charani P, Mohammadi-Rovshandeh J, Hashemi SJ, Kazeni-Nafaji S. Influence of dimethyl formamide pulping of bagasse on pulp properties. Biores Technol 2006; 97(18): 2435-42.

[38] Ziaie-Shirkolaee Y, Mohammadi-Rovshandeh J, Rezayati-Charan $\mathrm{P}$, Khajeheian MB. Influence of dimethyl formamide pulping of wheat straw on cellulose degradation and comparison with Kraft process. Biores Technol 2008; 99(9): 3568-78.

[39] Rodríguez A, Pérez A, De la Torre MJ, Ramos E, Jiménez L. Neural fuzzy model applied to ethylene-glycol pulping of non-wwod raw materials. Biores Technol 2008; 99: 965-74.

[40] Jiménez L, Serrano L, Rodríguez A, Ferrer A. TCF bleaching of soda-anthraquinone and diethanolamina pulp from oil palm empty fruit bunches. Biores Technol 2009; 100: 1478-81.

[41] Rodríguez A, Serrano L, Moral A, Jiménez L. Pulping of rice straw with high-boiling point organosolv solvents. Biochem Eng J 2008; 42: 243-7.

[42] Jiménez L, Rodríguez A, Calero AM, Eugenio ME. Use of ethanolamene-soda-water mixtures for pulping olive wood trimmings. Chem Eng Res Design 2004; 82(8): 1037-42.

[43] Jiménez L, Rodríguez A, Díaz MJ, López F, Ariza J. Organosolv pulping of olive tree trimminings by use of ethylene gly$\mathrm{col} /$ soda/water mixtures. Holzsforchung 2004; 58: 122-8.

[44] Jiménez L, Angulo V, Caparrós S, Pérez A, Ferrer JL. Neural fuzzy modeling of ethanolamine pulping of vine shoots. Biochem Eng J 2007; 34: 62-8

[45] Jiménez L, Pérez A, De la Torre MJ, Moral A, Serrano L. Characterization of vine shoots, cotton stalks, Leucaena leucocephala, and Chamaecytisus proliferus, and of their ethyleneglycol pulps. Biores Technol 2007; 98: 3487-90.

[46] Jiménez L, Angulo V, Rodríguez A, Sánchez R, Ferrer A. Pulp and paper from vine shorts: neural fuzzy modeling of ethylene glycol pulping. Biores Technol 2009; 100: 756-62.

[47] Rubio M, Tortosa JF, Gómez D, Miñana A, Soler A. El fraccionamiento de los materiales vegetales mediante procesos combinados de autohidrólisis-organosolvólisis. Afinidad 1994; 51: 95-102.

[48] Thompson NS, Ed. Hemicelluloses. In: Encyclopedia of chemical technology. John Wiley and Sons: USA 1995; vol. 13: pp. 54-72.

[49] Sun R, Lawther JM, Banks WB. Fractional and structural characterization of wheat straw hemicelluloses. Carbohydr Polym 1996; 29: 352-61

[50] Jiménez L, Caparrós S, Ariza J. Autohidrólisis de las hemicelulosas en la fabricación de pasta de papel. Ing Quím 2008; 462(9): 17893

[51] Boussarsar H, Rogé B, Mathlouthi M. Optimization of sugarcane bagasse conversión by hydrothermal treatment for the recovery of xylose. Biores Technol 2009; 100: 24: 6537.

[52] Dogaris I, Karapati S, Mamma D, Kalogeris E, Kekos D. Hydrothermal processing and enzymatic hydrolysis of sorghum bagasse for fermentable carbohydrates production. Biores Technol 2009; 100(24): 6543-9.

[53] Caparrós S, Ariza J, López F, Díaz MJ. Optimizing cellulosic paper obtained from Aroundo donax L. Ander hydrothermal treatment. J Ind Eng Chem 2007; 13(3): 465-73.

[54] Caparrós S, Ariza J, López F, Nacimiento JA, Garrote G, Jiménez L. Hydrothermal treatment and ethanol pulping of sunflower stalks. Biores Technol 2008; 99(5): 1368-72.

[55] Caparrós S, Díaz MJ, Ariza J, López F, Jiménez L. New perspective for Paulownia fortunei L. Valorisation of the authohydrolysis and pulping processes. Biores Technol 2008; 99(4): 741-9.

[56] Jiménez L, Angulo V, De la Torre MJ, Ramos E, Caparrós S, Pérez A. Simulación del tratamiento hidrotérmico aplicado a los sarmientos de vid, como etapa previa en la producción de pasta celulósica Afinidad 2006; 63(524): 277-85.

[57] Alfaro A, Rivera A, Pérez A, Yáñez R, García JC, López F. Integral valorization of two legumes by autohydrolysis and organosolv delignification. Biores Technol 2009; 100(1): 440-5. 
[58] Yáñez R, Garrote G, Díaz MJ. Valorization of a leguminous specie, Sebasnia grandiflora, by means of hydrothermal treatment. Biores Technol 2009; 100(24): 6514-523.
[59] Rodríguez A, Moral A, Sánchez R, Requejo A, Jiménez L. Influence of variables in the hidrotermal treatment of rice straw on the composition of the resulting fractions. Biores Technol 2009; 100: 4863-6.

Received: November 05, 2009

Revised: November 15, 2009

Accepted: November 24, 2009

(c) Jiménez and Rodríguez; Licensee Bentham Open.

This is an open access article licensed under the terms of the Creative Commons Attribution Non-Commercial License (http://creativecommons.org/licenses/ by-nc/3.0/) which permits unrestricted, non-commercial use, distribution and reproduction in any medium, provided the work is properly cited. 